\title{
Ischemic Stroke of Midbrain and Cerebellum Involving Reticular Activating
} System

\author{
Waleed Sadiq $^{1}$, Madeeha Subhan ${ }^{2}$ \\ 1. Internal Medicine, Shifa International Hospital, Islamabad, PAK 2. Capital Hospital Islamabad, Ayub \\ Teaching Hospital, Abbottabad, Islamabad, PAK
}

$\square$ Corresponding author: Waleed Sadiq, waleedsadiq01@gmail.com

Disclosures can be found in Additional Information at the end of the article

\section{Abstract}

The reticular activating system is the part of the brain that maintains the sleep/wake cycle. Any damage to this region can cause hypersomnolence and drowsiness along with altered sensorium. This case presents a patient with cerebellar and midbrain stroke with infarct of the reticular activating system, leading to hypersomnolence, drowsiness, and altered sensorium.

Categories: Internal Medicine, Neurology

Keywords: midbrain, ascending reticular activating system, stroke

\section{Introduction}

Hypersomnia is defined as excessive daytime sleepiness, which may follow a stroke. Persistent hypersomnia was reported in only five percent of stroke patients [1]. Diffusion tensor tractography (DTT) has enabled a three-dimensional reconstruction and estimation of the activated reticular activating system in the live human brain [2]. The reticular acting system is a complex neural network connecting the reticular formation of the brainstem to the cerebral cortex through excitatory relays in the intralaminar nuclei of the thalamus. Assessing the ascending reticular activating system (RAS) is crucial in the diagnosis and management of patients with impaired consciousness [3]. Strokes of the midbrain can affect the RAS and lead to hypersomnia and cognitive impairment.

\section{Case Presentation}

Received 08/23/2017

Review began 08/27/2017 Review ended 08/29/2017 Published 09/01/2017

(C) Copyright 2017

Sadiq et al. This is an open access article distributed under the terms of the Creative Commons Attribution License CC-BY 3.0., which permits unrestricted use, distribution, and reproduction in any medium, provided the original author and source are credited.
A 67-year-old man with a medical history of hypertension and diabetes mellitus presented to the emergency department with altered sensorium and drowsiness for the prior six hours. He was talking with his wife when she noticed the symptoms. The patients had no loss of consciousness, headache, vomiting, urinary incontinence, or seizure before or after the symptoms started. His hypertension was diagnosed five years prior and was well controlled with angiotensin-converting enzyme inhibitors. His diabetes was controlled by insulin; his last recorded $\mathrm{HbA1c}$ was $6.9 \%$. The patient reported that he is a smoker, and he is married with nine children. He avoids alcohol and eats a healthy diet. His family history is positive for stroke (his father). When he presented to the emergency department, his blood glucose level was 490 $\mathrm{mg} / \mathrm{dL}$, his blood pressure was 130/90 $\mathrm{mmHg}$, his pulse was $81 \mathrm{bpm}$, and his respiratory rate was 19 breaths per minute. His Glasgow coma scale was 15/15, we noted horizontal nystagmus in both eyes, and the patient was drowsy. His gait was unsteady, and he was swaying towards the left side. He could not perform the heel-to-shin test on both sides, and his response to the finger-to-nose test was more affected on the left side. His reflexes were pendular in the lower 


\section{Cureus}

extremities. We noted no facial asymmetry. The patient's motor strength was $4 / 5$ bilaterally in his upper and lower extremities. Sensations including fine touch, pain, vibration, and proprioception were intact. The patient's response to the Babinski reflex test was normal. Based on these findings and unremarkable respiratory, cardiovascular, and gastrointestinal findings, we applied a stroke protocol, and the patient was started on regular insulin infusion, atorvastatin, aspirin, and we inserted a nasogastric tube. We chose to manage the patient conservatively. Laboratory evaluation results are presented in Table 1 and Table 2.

\begin{tabular}{l|l}
\hline ESR & $108 \mathrm{~mm} / \mathrm{h}$ \\
\hline Hemoglobin & $127 \mathrm{~g} / \mathrm{L}$ \\
\hline White blood cells & $19.2 \times \times 109 / \mathrm{L}$ \\
\hline Red blood cells & $4.2 \times 1012 / \mathrm{L}$ \\
Platelets & $326.2 \times 109 / \mathrm{L}$ \\
MCV & $82.4 \mathrm{fL}$
\end{tabular}

\section{TABLE 1: Complete blood picture}

\section{Sodium}

Potassium

Glucose

Total bilirubin

Alanine aminotransferase

Alkaline phosphatase

Urea nitrogen

Creatinine

\section{$129 \mathrm{mmol} / \mathrm{L}$}

$3.9 \mathrm{mmol} / \mathrm{L}$

$16.4 \mathrm{mmol} / \mathrm{L}$

$61.88 \mu \mathrm{mol} / \mathrm{L}$

$0.566 \mu \mathrm{kat} / \mathrm{L}$

$7.3 \mu \mathrm{kat} / \mathrm{L}$

$7.1 \mathrm{mmol} / \mathrm{L}$

$97.2 \mu \mathrm{mol} / \mathrm{L}$

\section{TABLE 2: Complete metabolic profile}

Radiological (computed tomography without contrast) findings are presented in Figure 1 . We noted an effacement of cerebellar folia in a hypodense area of the hyperacute ischemic infarct of the left cerebellar hemisphere. We also noted a tiny lacunar infarct in the left basal ganglia and mild cerebral atrophy, as shown in Figure 1. Results of diffusion tensor tractography showing thinning of the left lower reticular activating system as compared to the right, as shown in Figure 2. 


\section{Cureus}

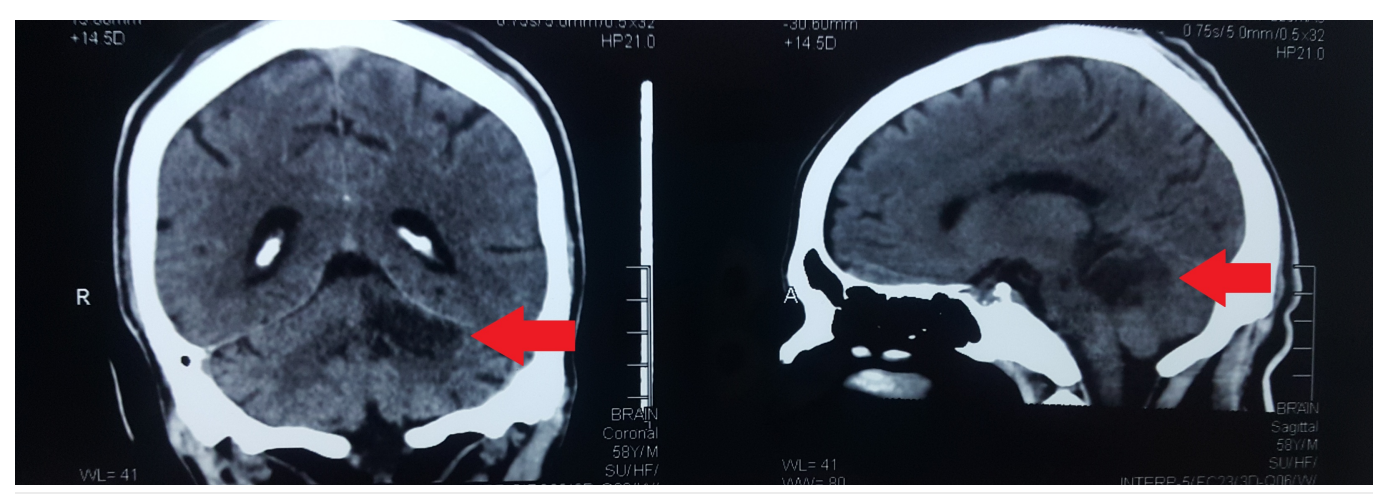

FIGURE 1: Ischemic infarct of left cerebellar hemisphere

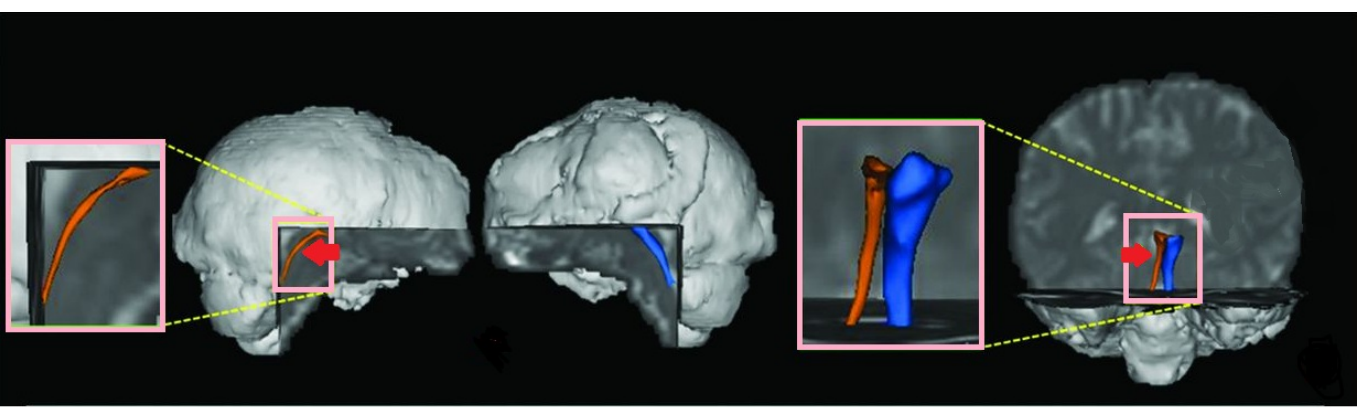

\section{FIGURE 2: Diffusion tensor tractography showing thinning of the left lower reticular activating system}

\section{Discussion}

Stroke is a major cause of mortality and morbidity in both developing and developed countries. The RAS is associated with hypersomnia. A few studies using DTT have reported an association ascending RAS injury with hypersomnia [4-5]. To our knowledge, there have been few cases of cerebellar midbrain infarct involving the RAS causing drowsiness and hypersomnia. Many studies have suggested that the involvement of the ascending RAS might be the mechanism of hypersomnia in stroke patients. A case study ascribed narcolepsy to damage of the ventral ascending RAS in a patient with a traumatic brain injury [5]. Many studies have reported the hypothalamus is associated with hypersomnia; thus, the recovery of the patient's hypersomnia was due to the recovery of an injured lower ascending RAS [6]. As introduced by Moruzzi and Magoun in 1949, the basis of arousal in the brainstem has been linked to the ascending RAS [7]. The infarct of the midbrain and cerebellum involving the ascending RAS caused our patient to be hypersomnolent. During his stay and subsequent follow-up evaluations, the patient's family reported that he was sleeping around 18 hours a day with an inability to perform the activities of daily living.

\section{Conclusions}

Our results suggest that patients presenting with nystagmus, hypersomnolence, and drowsiness must be assessed for RAS damage along with cerebellar and midbrain damage. Given this study is a case report, further studies with larger patient samples are necessary to 
validate our findings. In addition, the critical region of the RAS for hypersomnolence and drowsiness should be studied further. Therefore, any stroke patient presenting with altered sensorium, drowsiness, and sleeping while talking should undergo DTT to assess the extent of RAS damage.

\section{Additional Information \\ Disclosures}

Human subjects: Consent was obtained by all participants in this study. Conflicts of interest: In compliance with the ICMJE uniform disclosure form, all authors declare the following:

Payment/services info: All authors have declared that no financial support was received from any organization for the submitted work. Financial relationships: All authors have declared that they have no financial relationships at present or within the previous three years with any organizations that might have an interest in the submitted work. Other relationships: All authors have declared that there are no other relationships or activities that could appear to have influenced the submitted work.

\section{References}

1. Harris AL, Elder J, Schiff ND, Victor JD, Goldfine AM: Post-stroke apathy and hypersomnia lead to worse outcomes from acute rehabilitation. Transl Stroke Res. 2014, 5:292-300.

10.1007/s12975-013-0293-y

2. Edlow BL, Takahashi E, Wu O, et al.: Neuroanatomic connectivity of the human ascending arousal system critical to consciousness and its disorders. J Neuropathol Exp Neurol. 2012, 71:531-546. 10.1097/NEN.0b013e3182588293

3. Yeo SS, Chang PH, Jang SH: The ascending reticular activating system from pontine reticular formation to the thalamus in the human brain. Front Hum Neurosci. 2013, 7:416. 10.3389/fnhum.2013.00416

4. Jang SH, Yeo SS: Injury of the lower ascending reticular activating system in patients with pontine hemorrhage. Medicine (Baltimore). 2016, 95:5527. 10.1097/MD.0000000000005527

5. Jang SH, Seo WS, Kwon HG: Post-traumatic narcolepsy and injury of the ascending reticular activating system. Sleep Med. 2016, 17:124-125. 10.1016/j.sleep.2015.09.020

6. Tezer FI, Pektezel MY, Gocmen R, Saygi S: Unusual presentation of hypothalamic hamartoma with hypersomnia in an adult patient. Epileptic Disord. 2014, 16:366-369. 10.1684/epd.2014.0669

7. Moruzzi G, Magoun HW: Brain stem reticular formation and activation of the EEG 1949 (classical article). Electroencephalogr Clin Neurophysiol. 1995, 7:251-267. 10.1176/jnp.7.2.251 